\title{
Regressions on Monthly Stream Discharge to Predict Sediment Inflow to a Reservoir in Algeria
}

\author{
Kamel Khanchoul (Corresponding author) \\ Department of Geology, Badji Mokhtar University, Annaba, Algeria \\ Tel: 213-779-426-552_E-mail:kkhanchoul@yahoo.fr
}

Mohamed Benslama

Department of Biology and Ecology, Badji Mokhtar University, Annaba, Algeria

E-mail: bensmohand@yahoo.fr

Boualem Remini

Department of Water Sciences and Environment, University of Blida, Algeria

E-mail: reminib@yahoo.fr

\begin{abstract}
An understanding of the quantity of sediment deposited in a reservoir is necessary for effective reservoir and basin management. Sedimentation affects the useful life of a reservoir as flood control and water supply. The present study has been carried out to assess sediment load in the wadi Bouhamdane in northeast Algeria to be able to estimate sedimentation in a reservoir located upstream of the gauging station. Measurement data of suspended sediment and water discharge were available during 13-year period (1975/76-1987/88) in the Medjez Amar gauging station. The data were provided by the National Agency of Hydraulic Resources, which carried out the sampling and initial calculations of concentration. Several data sets, derived from daily mean water discharges and daily mean suspended sediment discharges were used to develop sediment rating curves for small periods of time when water sampling was insufficient. Relationships between monthly mean water discharge and monthly sediment load were used according to single and seasonal ratings. Additionally, a technique was devised to correct for log-transform bias on the sediment rating curves. Once the water discharge-sediment rating curves were defined, they were used with water discharge data to predict monthly and annual sediment inflow to the reservoir. The sediment rating estimates were judged adequate to predict the Bouhamdane reservoir fill. The total suspended sediment load carried by the wadi Bouhamdane from 1975/76 to 1987/88 was calculated to $3.90 \times 10^{6}$ tonnes and the mean annual sediment yield was $271 \mathrm{~T} \mathrm{~km}^{-2} \mathrm{yr}^{-1}$. During the reservoir period 1988/89 to $2006 / 2007$ the water discharge-sediment rating curves gave $5.38 \times 10^{6}$ tonnes. In terms of sediment entrapment in the reservoir by damming, the sedimentation in the reservoir during the 19-year period was predicted to be $6.29 \times 10^{6} \mathrm{~m}^{3}$. This study has estimated a loss of storage in the reservoir due to sedimentation of $0.17 \% \mathrm{yr}^{-1}$.
\end{abstract}

Keywords: Bouhamdane, Watershed, Sediment load, Reservoir, Algeria

\section{Introduction}

Because of increasing concerns on water quality and aquatic habitat, the need to quantify, and predict sediment yield at a watershed level has become important. Models for sediment yield provide invaluable information when applied to those areas lacking of data, for predicting future impacts of agricultural activities, land use, stream stabilization and sediment storage in reservoirs. Information on the suspended sediment concentration of the wadi Bouhamdane, which can be used to calculate a value of suspended sediment yield must be seen as a key requirement in any attempt to understand the sediment dynamics of the river basin, and to quantify the amounts of sediment involved in order that effective soil conservation measures may be adopted and the reservoir's lifespan and capacity may be maintained for important purposes as water supply and irrigation practices. It should, however, be pointed out that such information was impossible to assemble after 1988 because the gauging station, located downstream of the dam, has not been relocated upstream. 
Additionally, given the absence of fluvial sediment monitoring programs, and that long-term investigations in this reservoir do not exist, they do not offer any potential for reconstructing the history of sedimentation over the past 19 years.

Notwithstanding the problem of obtaining reliable sediment load from long-term sediment concentration measurements, the present study is focussed on providing information on the sediment input into the reservoir. The aim of this study was to develop a methodology using measured suspended sediment load at the Bouhamdane watershed outlet from 1975/76 to 1987/88 and estimate the sediment yield in order to predict the rate of sediment generation to the reservoir during the period 1988/89-2006/2007. A key element for sediment assessment was the use of suspended sediment rating curves which have been widely used to estimate sediment load when and where measured data are not available (Asselman, 2000; Horowitz, 2003). In this paper regression relationships are developed between daily values of suspended sediment discharge and water discharge, and also between monthly sediment load and mean monthly discharge to predict the sediment flux to the reservoir.

\section{Brief description of the study area}

The Bouhamdane watershed, controlled downstream by the Medjez Amar gauging station, belongs to the Seybouse basin $\left(6475 \mathrm{~km}^{2}\right)$. It drains an area of $1105 \mathrm{~km}^{2}$ and shows the existence of a dam $2 \mathrm{~km}$ upstream of this station (Figure 1). Based on information collected from the Agency of Algerian Dams in Algiers, the Bouhamdane dam, that construction started in 1980 and completed in September 1988, had intended purposes which include providing water for irrigation and city water supply, retaining wet season flow to minimise downstream flood risk, and creating habitat for fish and wildlife. This reservoir is a zoned earth and rock dam with a central clay core and an average depth of $6 \mathrm{~m}$. It has a total capacity of $2.00 \times 10^{8} \mathrm{~m}^{3}$ with a reservoir watershed area of $1070 \mathrm{~km}^{2}$. No information was available concerning the considered sedimentation when designing the Bouhamdane dam.

The basin with the highest elevation of $1281 \mathrm{~m}$ and the lowest of $270 \mathrm{~m}$ is dominated by Oligocene sandstone beds and Oligo-Miocene conglomerate with important proportion of erodible rocks (marl and clay) and unconsolidated Quaternary deposits. Sandstones were weathered under the humid climatic conditions, yielding the soils particularly susceptible to erosion and coarsening through the loss of fine particles. The extended piedmonts are covered by thick silty-clayey soils, with variable slope steepness $\left(4^{\circ}-15^{\circ}\right)$.

$<<$ Fig. 1. Location map of the: 1- Bouhamdane watershed; 2- Saf Saf watershed $>>$

The land is mainly used for farming occupying $57 \%$ of the watershed area and the main crop is wheat. In the mountainous parts of the watershed, the land is mainly covered with forests and sparse bush. The local subhumid climate of the Mediterranean type is characterized by a distinct wet (November-May) and dry (June-October) season and the mean annual precipitation lies in the range of $528-611 \mathrm{~mm}$. An average annual rainfall of 579 $\mathrm{mm}$ at the four rainfall stations (Figure 1) and a mean annual temperature of $18^{\circ} \mathrm{C}$ are recorded in the basin. Most rain showers and occasional intense storms occur during November, December, January and May and may produce quite high cumulative rainfall. As an example, in December, 1984/85, a 3-day rainstorm produced 220 $\mathrm{mm}$.

Mean annual discharge at the Medjez Amar gauging station (period 1975/76-1987/88) was $2.79 \mathrm{~m}^{3} \mathrm{~s}^{-1}$. Because of the dam construction and opening since December 1988, the mean annual water discharge has been reduced to $1.71 \mathrm{~m}^{3} \mathrm{~s}^{-1}$ (December 1988 to August 2007). The total volume of water entering in the reservoir from 1988/89 to $2006 / 2007$ was estimated to be $1.65 \times 10^{9} \mathrm{~m}^{3}$ and the volume of water stored in the reservoir for the 19-year period was $1.19 \times 10^{8} \mathrm{~m}^{3}$.

\section{Data and method}

The collection of the hydro-climatic data and suspended sediment concentrations for the period between 1975/76 and 2006/2007 was possible with the collaboration of the different services of the National Agency of Hydraulic Resources (ANRH) of Annaba and Constantine. In the instrumented watershed, precipitation was recorded by four manual gauges and four automatic tipping bucket gauges. The stations were located at : Ouled Habeba (elevation of $980 \mathrm{~m}$ ), Bouhamdane dam (360 m), Medjez Amar (250 m) and Guelma (301 m) (Figure 1).

Sediment and water discharges were measured at the gauging station. The site was operated with an automatic stage recorder and manual water sampling. These were supplemented by visual stage recording during low, medium and high streamflows.

The sediment was sampled using one liter dip sampler. One or two samples were taken by measurement in the middle of the wadi and/or at its edge. Suspended matter concentrations were determined by filtration of the 
samples on pre-weighted fiberglass filters $(0.45 \mu \mathrm{m}$, watman $\mathrm{GF} / \mathrm{F})$, then dried and weighed (Achite and Ouillon, 2007).

The instantaneous values of suspended sediment were sampled in variable time intervals during storm flows. The samples were often more numerous in periods of flood peaks with short time intervals (sampling frequency every 30 or 60 minutes), whereas in low flow or when the water discharge was constant during the day, a minimum of sampling was done ( 1 to 2 water samples a day). For the period 1975-1988, nearly all high-water events were sampled. After December 1988, suspended sediment concentrations were measured occasionally but the water stage was recorded and the discharges calculated at the reservoir.

This study is made in two steps. In the first step, we analysed the relationship of sediment discharge versus water discharge to estimate the monthly and annual sediment load for the period 1975/76-1987/88. In the second step, we focused on developing a relationship between monthly sediment load and monthly water discharge during the period 1975/76-1987/88 to be able to predict the sediment inflow to the reservoir during 1988/89-2006/2007.

Daily mean water discharge data were obtained for the wadi Bouhamdane. However, before computing the mean daily suspended sediment discharges, it was necessary to reconstitute the missing concentration values of the 24-hour storm events by making use of the relationship between instantaneous concentration and instantaneous water discharge for the best among the power and exponential functions. The data set consists of 906 measurements of instantaneous suspended sediment concentrations and the corresponding water discharges. The regressions of the instantaneous data were used to be included in the calculation of daily mean sediment discharges during days with additional sampled data. After that, sediment rating curves were created from the daily mean suspended sediment discharge and the daily mean water discharges for the period 1975/76-1987/88 (Table 1). The most common used relationship of a rating curve is a power function (Walling, 1977; Asselman, 2000; Achite and Ouillon, 2007) of the type:

$$
\mathrm{Qs}=\mathrm{aQ}^{\mathrm{b}}
$$

in which Qs is the daily mean suspended sediment discharge in $\mathrm{kgs}^{-1}$, Q is the daily mean water discharge in $\mathrm{m}^{3} \mathrm{~s}^{-1}$, and $\mathrm{a}$ and $\mathrm{b}$ are the rating curve parameters.

$<<$ Table 1 . Sediment rating curves developed on daily water and sediment discharges $>>$

The use of sediment discharge as a dependent variable has been criticized because Q is included both in the dependent variable and in the independent variable of the regression equation, and therefore gives an increased correlation coefficient (McBean and Al-Nassri, 1988). However, the conclusion by the later authors that the correlation between sediment concentration and water discharge is more correct than the correlation between sediment discharge and water discharge has been contradicted by some researchers (Annandale, 1990; Milhous, 1990; Nordin, 1990). Jansson (1997) showed in her study that regressions developed on log-loads and log-concentrations, both of which are back-transformed and corrected for bias, give equally high sediment transport.

An attempt has been made to subdivide the data set according to seasonal effects, namely, wet season (November-May) and dry season (June-October). Figure 2, and tables 1 and 2 show rating curves of the wadi Bouhamdane. In figures $2 \mathrm{a}$ and $\mathrm{b}$, the best-fit power function lines (dashed lines) through the data underestimate the suspended sediment flux at high water discharges, and it is important for the high water discharges to be accurately represented because the vast majority of the suspended sediment is transported during these very high discharge events. Thus, by dividing the data into low-medium and high flow regimes subdivided sediment rating curves were created. The divisions were chosen somewhat arbitrarily based on the apparent changes in the slope of the rating curves. Figure 2 provides examples of subdivided sediment rating curves for the Bouhamdane, showing the recalculated regressions for the different flow regimes and the better fit sediment rating curve (solid lines) through the high flow discharges.

$<<$ Fig. 2. Relation of daily water discharge and daily sediment discharge according to : (1) single rating; (2) wet season; (3) dry season; a) rating from a single best-fit calculation; b) rating from low-medium flow; c) rating from high-flow. No high-flow and discharge-sediment threshold during dry season so just a single regression is represented $>>$

$<<$ Table 2. Sediment rating curves developed on monthly mean water discharge and monthly sediment load $>>$

Ferguson (1986) and Walling (1988) have highlighted an underestimation bias inherent in the use of log-transformed regression to derive rating relationships. They have suggested that this bias represents a major cause of the error associated with rating curve estimates and that it can be largely removed by applying a simple 
correction factor based on the standard error of the estimate of the logarithmic regression. Jansson (1985) and Fergusson (1986) proposed a correction factor for base-10 logarithms:

$$
\mathrm{CF}=\exp \left(2,65 \sigma^{2}\right)
$$

where $\sigma^{2}$ is the variance in base-10 logarithms.

The corrected equation becomes:

$$
\mathrm{Qs}=\mathrm{CF} \times \mathrm{aQ}^{\mathrm{b}}
$$

After the composed rating curves had been created and corrected, the sediment rating curves were applied to determine the cumulative volume of suspended sediment that had passed the gauging station during the period of record (1975-1988). The rating curves were used to calculate monthly and annual mean suspended sediment flux.

After that, rating relationships were developed by using power regressions on the calculated monthly sediment loads (in tonnes) and monthly mean water discharge (in $\mathrm{m}^{3} \mathrm{~s}^{-1}$ ) by using one rating curve for the total set of data, and seasonal rating curves for the wet and dry seasons during the period 1975/76-1987/88 (Figure 3). These water discharge-sediment load ratings were made to predict sediment inflow to the reservoir during the period with no sediment measurements. Monthly values were used because the range of errors associated with the corresponding flux estimates for relatively short time-frames (e.g. daily) were likely to be substantially larger than those associated with longer time-frames (e.g. monthly, annually). This is because, in short time-frames, the over-predictions and under-predictions do not have sufficient time to balance each other (Horowitz, 2003). Figures $3 \mathrm{a}$ and $3 \mathrm{~b}$ show respectively a considerable over-estimation and a slightly underestimation of the sediment load, and as can be seen, it is difficult to get good rating curves. To make rating curves composed of sub-regressions, the data base was divided into groups of data to create representative rating curves that fit the data and shows a water discharge threshold (Figure 3).

$<<$ Fig. 3. Relation of monthly discharge and monthly sediment load according to: (1) single rating; (2) wet season; (3) dry season; a) rating from a single best-fit calculation; b) rating from low-medium flow; c) rating from high-flow. No high-flow and discharge-sediment threshold during dry season so just a single regression is represented $>>$

Fairly significant uncertainty exists when estimating suspended sediment load using the rating curve technique described above because both sampling error and statistical error must be considered. Thus, to remove the inherent bias as a result of log-transformation, we used equation (2). However, this equation can give an over-estimation of the sediment when it is used for small samples (e.g. power function in Figure 3b). Helsel and Hirsch (1992) proposed the "smearing estimate" by Duan (1983) as the most generally applicable correction factor to be used for small samples ( $<10$ values). The smearing estimate is defined as:

$$
\mathrm{C}_{\mathrm{f}}=\frac{\sum_{\mathrm{i}=1}^{\mathrm{N}} \exp (\mathrm{ei})}{\mathrm{N}}
$$

where ei $=$ the residuals from the used exponential functions, which are the differences in the natural logarithms of measured and computed sediment load.

The loads by the various rating relationships of daily flow were compared with the loads calculated from the measured suspended sediment load (Table 3a). The loads by the monthly water discharge-sediment relationships were compared with monthly load containing measured load plus $71 \%$ load as calculated by the daily sediment rating curves (also used in the development of the relationships) (Table 3b). Errors have been calculated and expressed as a percentage of the value calculated from the "measured" data as follows:

$$
\text { Error }(\%)=\left(\frac{\text { Rating curve estimate }}{\text { Continuous record load }}-1\right) \times 100
$$

In addition to suspended sediment, reservoirs can also trap bed load. Because of a lack in bed load measurements, empirical relations originally derived by Maddock from different environments (Lane and Borland, 1951) were used. Wadi Bouhamdane with gravel, stones, boulders, and some sand, forming the channel bed would give a bed load in the range of $5-12 \%$ of the suspended material load. 


\section{Results and discussion}

\subsection{Reliability of the rating relationships}

The use of the sediment rating curves has given satisfactory results. The errors in the sum of loads by using the relationship between daily sediment discharge and water discharge compared with the sum of loads from days with measurements (but including instantaneous sediment concentrations from relationships), demonstrate that sediment loads calculated by using a single rating curve on daily values without a seasonal division may over-estimate the load by $2 \%$, and the seasonal ratings may under-estimate the load by $3 \%$ (Table $3 a$ ). The use of rating curves developed from monthly sediment load in association with monthly mean water discharge could provide a different level of accuracy in estimates of loads of around $11 \%$ error with a single rating and ratings distinguished by season (Table 3b). After correction for bias, the error in sediment load under-estimation was changed from $46 \%$ to $7 \%$. The total error by using the two steps in the estimation of the loads through daily and monthly rating curves was for the single rating curves an underestimation of $5.20 \%$ and for the seasonal ratings $20.90 \%$.

$<<$ Table 3. Comparison of rating curve estimates of sediment load with loads calculated from measurements $>>$

The need properly to assess the sediment yield estimates is particularly pressing where the sediment rating curves could not provide reliable estimates of the sediment load accumulated in the Bouhamdane reservoir. Since reservoir sedimentation survey data for the Zardézas dam (from 1982 to 1992) and records of water and sediment discharge in the Saf Saf watershed are available for the period 1975/76-1980/81, a comparison could be made between the results of the calculated sediment load using sediment rating curves and the value of trapped sediments in the Zardézas reservoir. The Saf Saf catchment is located $6 \mathrm{~km}$ upstream of the Zardézas dam and has an area of $322 \mathrm{~km}^{2}$ at the hydrometric station Khemakhem.

The hydrometric record for the Saf Saf watershed consists of continuous daily measurements of water discharge and intermittent measurements of suspended sediment concentration for the period 1975/76-1980/81. The suspended sediment discharges were plotted against the corresponding water discharge measurements. The main reason for using sediment discharge instead of concentrations is in order to compare the results of this analysis with those of the Bouhamdane research which also investigated the sediment discharge rating curve. Predictions made using equation in figure 4 , where the parameters have been fitted by linear least-squares following a log-transform, are known to be biased because of the application of the log-transform. The method for correcting this bias is shown in equations 2 and 3 and figure 4 . The calculated and measured sediment loads achieved using a sediment rating curve on daily sediment discharge and daily mean water discharge are presented in table 4 . Then the monthly suspended sediment fluxes, for the period 1975/76-1980/81, were calculated by transforming the each daily flow in suspended discharge using the sediment rating curve, and accumulating this information to monthly and annual levels. A sediment rating curve was then created and corrected for bias for the gauged wadi from the monthly sediment load and monthly mean water discharge (Figure 5). In applying this monthly sediment rating curve technique to assist in establishing the suspended sediment of the Saf Saf watershed on monthly mean water discharges related to the period 1982-1992, the calculations have given a total sediment load of $2.00 \times 10^{6}$ tonnes.

$<<$ Fig. 4. Relation of daily mean water discharge and daily sediment discharge for the Saf Saf watershed $>>$

$<<$ Table 4. Comparison between "measured" sediment load and load from daily rating curves for the Saf Saf watershed $>>$

During the period 1982 to $1992,2.94 \times 10^{6} \mathrm{~m}^{3}$ of sediment was accumulated in the Zardézas reservoir. With a dry bulk density of $0.8 \mathrm{~g} / \mathrm{cm}^{3}$ the mass of the material accumulated in the reservoir during this period was calculated to be about $2.35 \times 10^{6}$ tonnes. The sediment deposits in the reservoir were carried out and then estimated by dredging in 1958, 1982 and 1992. The suspended sediment load in the Saf Saf watershed (at the gauging station) was estimated using the technique of the sediment rating curves on daily suspended sediment and daily water discharge dataset. Thus, the estimated sediment load during the period 1982-1992, was equal to $2.02 \times 10^{6}$ tonnes. A bed load of $10 \%$ of the suspended load would give $0.20 \times 10^{6}$ tonnes of bed load (Khanchoul et al., 2007). Altogether the bed load and the suspended load at the hydrometric station during the period 1982 to 1992 would be $2.22 \times 10^{6}$ tonnes. The comparison of the sediment inflow of $2.22 \times 10^{6}$ tonnes with the material accumulated in the reservoir of $2.35 \times 10^{6}$ tonnes during the same period confirms that the calculated suspended sediment load in the wadi Saf Saf is of the right order of magnitude (Khanchoul et al., 2007). The difference of $0.13 \times 10^{6}$ tonnes taken from the Zardézas sedimentation may have been transported along the Saf Saf wadi downstream from the hydrometric station into the reservoir or may be due errors in measurement or estimation. 
$<<$ Fig. 5. Relation of monthly mean discharge and monthly sediment load for the Saf Saf watershed $>>$

With this qualification in mind, it is clear that the prediction of the sediment yield accumulated in a reservoir can be assessed through the sediment rating curve procedure.

\subsection{Sediment load estimation}

The mean annual load for the period between 1975/76 and 1987/88 when sediment concentration data were collected at the gauging station, and $71 \%$ was estimated from sediment rating curves on daily data, the mean

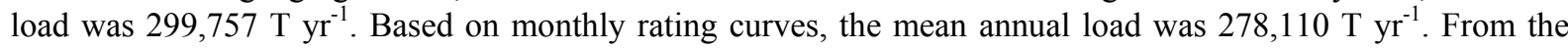
estimation of sediment load based on daily data and same density estimate as above, wadi Bouhamdane has an annual load of $3.90 \times 10^{6}$ tonnes and a mean annual sediment yield of $271 \mathrm{~T} \mathrm{~km}^{-2} \mathrm{yr}^{-}{ }^{1}$. Based on monthly rating curves the load is $3.62 \times 10^{6}$ tonnes or a mean annual sediment yield of $252 \mathrm{~T} \mathrm{~km}^{-2} \mathrm{yr}^{-1}$.

During the 19-year period with the reservoir 1988/89-2006/2007, the sediment rating curves using the monthly sediment load and water discharge relationship had to be used to calculate sediment transport. Hence, on the basis of the used monthly discharges, representing the reservoir watershed, the sediment load estimate using a single suspended sediment load-water discharge rating was equal to $5.38 \times 10^{6}$ tonnes. In order to assess the suspended sediment yield supplied to the river in the watershed, we divided the sediment flux by the whole watershed area $1070 \mathrm{~km}^{2}$ which gives $265 \mathrm{~T} \mathrm{~km}^{-2} \mathrm{yr}^{-1}$.

Additionally, based on some studies undertaken in Algerian reservoirs, Remini (2005) estimated that $15 \%$ of the sediment flux passed through the Bouhamdane dam. Therefore, the present estimation of suspended sediment flux deposited in the reservoir would be $4.57 \times 10^{6}$ tonnes.

Bedload is likely to account for a higher fraction of total load during periods after storms owing to the coarse material supplied by rainfall-triggered landslides. A large proportion of this bedload may be trapped downstream in coarse floodplains. However, bed material load contributes the lowest percentage of the total load, with contribution of approximately $10 \%$ (Walling, 1987). With this rate, the bed load was evaluated to be $0.46 \times 10^{6}$ tonnes and the total load entering the reservoir would be $5.03 \times 10^{6}$ tonnes. Considering a wet bulk density of 1.8 $\mathrm{g} / \mathrm{cm}^{3}$ and a dry bulk density of $0.8 \mathrm{~g} / \mathrm{cm}^{3}$ of the accumulated sediment according to the Agency of Algerian Dams (AAD), the total sediment volume accumulated in the reservoir for the whole period of dam operation was $6.29 \times 10^{6} \mathrm{~m}^{3}$.

According to the initial storage capacity of the reservoir of $2.00 \times 10^{8} \mathrm{~m}^{3}$ and the total amount of accumulated sediment in the reservoir, $3.15 \%$ of the total designed capacity was lost. The average annual loss in storage capacity reached $0.17 \% \mathrm{yr}^{-1}$. The study reservoir is dependent on the sediment yield from the watershed which, in turn, is dependent upon the rate of erosion and the transport, by water, of the sediment within the watershed. In this region where deforestation has occurred and the vulnerable terrains are more and more exposed to erosion, the dam relatively suffering from sedimentation will gradually increase in the near future, leading to a loss of its storage capacity.

Heavy and excessive rainfall triggers high water discharge and suspended sediment load. This shows the effect of a few days with extremely high suspended sediment transport, a trend similar to water discharge in the basin (Gupta and Chakrapani, 2007). A large proportion of the sediment deposited in the Bouhamdane reservoir is transported by the river in only a few days during the winter and spring seasons from December to April. The spatial distribution of accumulated sediment in the reservoir shows profoundly that the total incoming sediment remains in the reservoir and particularly at the uppermost parts (deltaic deposits).

\section{Conclusion}

As sediment yield in the Bouhamdane watershed has not been estimated since the construction of the reservoir, accurate estimation was necessary in forecasting the sediment load in watershed and therefore optimizing life time of the dam. Unfortunately, reservoir sedimentation survey data were not available in this study, so the rating curve method was used to provide a reasonable approximation of sediment yield estimates. To obtain both the long-term sediment load deposits in the reservoir and sediment flux in the Bouhamdane watershed (period 1988/89-2006/2007), relationships between daily mean suspended sediment discharge and daily mean water discharge data and then sediment rating curves were created using monthly sediment load and monthly mean water discharge relations during the period 1975/76-1987/88.

We suggested deriving sediment rating curves based on dividing the long-term database into two seasonal groupings. Bias-corrected optimal rating curves have given us good predictions and significantly have reduced estimation errors. Comparison of sediment load values for the river calculated from sediment concentrations 
collected through intense water sampling, with those obtained by using sediment rating curves, suggests that the sum of the calculated sediment loads were close to the sum of the predicted sediment values.

In order to test the effect of the sediment rating technique for predicting suspended sediment loads, reservoir sediment survey for the Zardézas reservoir were compared to the extrapolated sediment load estimates (period 1982-1992) from the constructed sediment rating curve based on monthly data at the gauged wadi Saf Saf for the period 1975/76-1980/81. The calculation has provided good criteria for an accurate prediction of sediment yield in the dam. It is evident that suspended sediment loads calculated from ratings relationships are likely to be reliable for sediment load extrapolation.

Results derived from the rating curve method not only have saved time in dealing with the large historical database but also have allowed us to reconstruct either by extrapolation the history of the sediment load, thereby permitting us to quantify watershed responses to human disturbances (e.g. dam and agriculture) as well as natural events. The 19-year sediment deposition in the Bouhamdane reservoir was accounted to $6.29 \mathrm{Mm}^{3}$ and the sediment yield in the reservoir watershed was $265 \mathrm{~T} \mathrm{~km}^{-2} \mathrm{yr}^{-1}$.

Since the life span of the reservoir is determined by the rate of sedimentation which gradually has reduced the storage capacity by $3.15 \%$, the siltation problem could destroy the ability to provide water and power in the near future. The worldwide average for the loss of storage due to sedimentation is between $0.5 \%$ and $1.0 \%$ per annum (White et al., 1999), a very significant amount compared to the average loss capacity of $0.17 \% \mathrm{yr}^{-1}$ in the study reservoir.

The main recommendation of this paper stems from the fact that a way to obtain a reliable estimate of sediment yield is by measuring suspended sediment concentration continuously at a gauging station not too far upstream of the reservoir, deriving the sediment rating curve relationships.

\section{References}

Achite, M., and Ouillon, S. (2007). Suspended sediment transport in a semiarid watershed, Wadi Abd, Algeria (1973-1995). Journal of Hydrology, 343, 187-202.

Annandale, G.W. (1990). Uncertainty in suspended sediment transport curves. Discussion. Journal of Hydraulic Engineering, 116(1), 140-141.

Asselman, N.E.M. (2000). Fitting and interpretation of sediment rating curves. Journal of Hydrology, 234, 228-248.

Duan, N. (1983). Smearing estimate-a nonparametric retransformation method. Journal of American Statistic Association, 78, 605-610.

Ferguson, R.I. (1986). River loads underestimated by rating curves. Water Resources Research, 22(1), 74-76.

Gupta, H., and Chakrapani, G.J. (2007). Temporal and spatial variations in water flow and sediment load in the Narmada river. Current Science, 92(5), 679-684.

Helsel, D.R., and Hirsch, R.M. (1992). Statistical methods in water resources. Amsterdam: Elsevier Publishers.

Horowitz, A.J. (2003). An evaluation of sediment rating curves for estimating suspended sediment concentration for subsequent flux calculations. Hydrological Processes, 17, 3387-3409.

Jansson, M.B. (1985). Sediment rating curves of the Ljusnan at Funaesdalen. Beitr. Hydrologie Sonderhft, 5(1), 219-233.

Jansson, M.B. (1997). Comparison of sediment rating curves developed on load and on concentration. Nordic Hydrology, 28 (3), 189-200.

Khanchoul, K., Jansson, M.B., and Lange, Y. (2007). Comparison of suspended sediment yield in two catchments, northeast Algeria. Zeitschrift für Geomorphologie, 51(1), 63-94.

Lane E.W., and Borland W.M. (1951). Estimating bed load. Transactions, American Geophysical Union. 32(1), 121-123.

McBean, E.A., and Al-Nassri, S. (1988). Uncertainty in suspended sediment transport curves. Journal of Hydraulic Engineering, 114(1), 63-74.

Milhous, R.T. (1990). Uncertainty in suspended sediment transport curves. Discussion. Journal of Hydraulic Engineering, 116(5), 730-732.

Nordin, C.F. (1990). Uncertainty in suspended sediment transport curves. Discussion. Journal of Hydraulic Engineering, 116(1), 145-148. 
Remini, B. (2005). La problématique de l'eau en Algérie. Collection hydraulique et transport solide. Imprimerie Madani, Blida, 101p.

Walling, D.E. (1977). Assessing the accuracy of suspended sediment rating curves for a small basin. Water Resources Research, 13, 531-538.

Walling, D.E. (1987). Rainfall, runoff and erosion of the land: a global view. Energetics of Physical Environment, Chichester: Wiley, 89-117.

White, W.R., Attewill, L., Ackers, J., and Wingfield R. (1999). Guidelines for the flushing of sediment from reservoirs. HR Wallingford. Report SR, 563.

Table 1. Sediment rating curves developed on daily water and sediment discharges

\begin{tabular}{|c|c|c|c|c|c|c|}
\hline Data group & $\begin{array}{c}\text { Discharge threshold } \\
\left(\mathrm{m}^{3} / \mathrm{s}\right)\end{array}$ & Equations & $\begin{array}{c}\sigma^{2} \text { of log } \\
\text { regression }\end{array}$ & $\mathrm{cf}$ & $\mathrm{r}$ & $\mathrm{n}$ \\
\hline \multirow{5}{*}{ Single rating } & One single regression & $\mathrm{Qs}=0.51 \mathrm{Q}^{1.31}$ & 0.085 & 1.25 & 0.95 & \\
& $\mathrm{Q}<74.29$ & $\mathrm{Qs}=0.55 \mathrm{Q}^{1.26}$ & 0.090 & 1.27 & 0.93 & 287 \\
& $\mathrm{Q} \geq 74.29$ & $\mathrm{Qs}=0.21 \mathrm{Q}^{1.52}$ & 0.024 & 1.07 & 0.94 & \\
\hline \multirow{3}{*}{ Wet season } & One single regression & $\mathrm{Qs}=0.51 \mathrm{Q}^{1.30}$ & 0.063 & 1.18 & 0.95 & \\
& $\mathrm{Q}<53.21$ & $\mathrm{Qs}=0.63 \mathrm{Q}^{1.20}$ & 0.064 & 1.18 & 0.90 & 251 \\
& $\mathrm{Q} \geq 53.21$ & $\mathrm{Qs}=0.16 \mathrm{Q}^{1.56}$ & 0.027 & $*$ & 0.95 & \\
\cline { 1 - 3 } Dry season & One single regression & $\mathrm{Qs}=0.65 \mathrm{Q}^{1.99}$ & 0.121 & 1.38 & 0.94 & 36 \\
\hline
\end{tabular}

* Bias correction not used because on one hand the coefficient of correction is high and on the other hand the correction will greatly overestimate the sediment load

Table 2. Sediment rating curves developed on monthly mean water discharge and monthly sediment load

\begin{tabular}{|c|c|c|c|c|c|c|}
\hline Data group & $\begin{array}{c}\text { Discharge threshold } \\
\left(\mathrm{m}^{3} / \mathrm{s}\right)\end{array}$ & Equations & $\begin{array}{c}\sigma^{2} \text { of } \log \\
\text { regression }\end{array}$ & $\mathrm{CF}_{-} \mathrm{C}_{\mathrm{f}}$ & $\mathrm{r}$ & $\mathrm{n}$ \\
\hline \multirow{5}{*}{ Single rating } & One single regression & $\mathrm{SL}=1.81 \mathrm{Q}^{1.58}$ & 0.177 & 1.60 & 0.94 & \\
& $\mathrm{Q}<0.77$ & $\mathrm{SL}=3.42 \mathrm{Q}^{1.98}$ & 0.115 & 1.36 & 0.87 & 156 \\
& $\mathrm{Q} \geq 0.77$ & $\mathrm{SL}=3.33 \mathrm{Q}^{1.15}$ & 0.205 & 1.72 & 0.79 & \\
\hline \multirow{3}{*}{ Wet season } & One single regression & $\mathrm{SL}=2.49 \mathrm{Q}^{1.29}$ & 0.121 & 1.38 & 0.93 & \\
& $\mathrm{Q}<12.12$ & $\mathrm{SL}=2.48 \mathrm{Q}^{1.28}$ & 0.128 & 1.41 & 0.90 & 91 \\
& $\mathrm{Q} \geq 12.12$ & $\mathrm{SL}=1.12 \mathrm{Q}^{1.59}$ & - & $\mathbf{1 . 0 2}$ & 0.82 & \\
\hline Dry season & One single regression & $\mathrm{SL}=3.78 \mathrm{Q}^{2.17}$ & 0.124 & 1.39 & 0.89 & 65 \\
\hline
\end{tabular}

Value in bold represents a correction factor using the smearing estimate

Table 3. Comparison of rating curve estimates of sediment load with loads calculated from measurements a- Comparison between "measured" sediment load and load from daily rating curves

\begin{tabular}{|c|c|c|c|c|}
\hline $\begin{array}{c}\text { Sediment load calculation } \\
(\mathrm{SL})\end{array}$ & $\begin{array}{c}\text { SL with } \\
\text { uncorr. Eq. } \\
10^{3} \text { tonnes }\end{array}$ & $\begin{array}{c}\text { Error } \\
\%\end{array}$ & $\begin{array}{c}\text { SL with } \\
\text { corr. Eq. } \\
10^{3} \text { tonnes }\end{array}$ & $\begin{array}{c}\text { Error } \\
\%\end{array}$ \\
\hline $\begin{array}{c}\text { Load from } 287 \text { days with } \\
\text { measurements, in } 10^{3} \text { tonnes }\end{array}$ & 3328 & & 3328 & -10.79 \\
\hline \hline $\begin{array}{c}\text { Single daily rating } \\
\text { (One single regression) }\end{array}$ & 2369 & -28.82 & 2969 & +2.04 \\
\hline $\begin{array}{c}\text { Single daily rating } \\
\text { (Two regressions) }\end{array}$ & 3104 & -6.73 & 3396 & -19.86 \\
\hline \hline $\begin{array}{c}\text { Seasonal daily ratings } \\
\text { (One single regression) }\end{array}$ & 2250 & -32.39 & 2667 & -2.94 \\
\hline $\begin{array}{c}\text { Seasonal daily ratings } \\
\text { (Two regressions) }\end{array}$ & 3154 & -5.23 & 3230 & \\
\hline
\end{tabular}


b- Comparison between load from daily estimations and monthly sediment load

\begin{tabular}{|c|c|c|c|c|}
\hline $\begin{array}{c}\text { Load from } 287 \text { days with } \\
\text { measurements, in } 10^{3} \text { tonnes }\end{array}$ & 3897 & 3897 & +73.36 \\
\hline $\begin{array}{c}\text { Single daily rating } \\
\text { (One single regression) }\end{array}$ & 4230 & +8.55 & 6756 & -7.24 \\
\hline $\begin{array}{c}\text { Single daily rating } \\
\text { (Two regressions) }\end{array}$ & 2104 & -46.01 & 3615 & -15.99 \\
\hline $\begin{array}{c}\text { Seasonal daily ratings } \\
\text { (One single regression) }\end{array}$ & 2372 & -39.13 & 3274 & -17.96 \\
\hline $\begin{array}{c}\text { Seasonal daily ratings } \\
\text { (Two regressions) }\end{array}$ & 2873 & -26.28 & 3197 & +197 \\
\hline
\end{tabular}

Table 4. Comparison between "measured" sediment load and load from daily rating curves for the Saf Saf watershed

\begin{tabular}{|c|c|c|c|c|}
\hline $\begin{array}{c}\text { Sediment load calculation } \\
(\mathrm{SL})\end{array}$ & $\begin{array}{c}\text { SL with } \\
\text { uncorr. Eq. } \\
10^{3} \text { tonnes }\end{array}$ & $\begin{array}{c}\text { Error } \\
\%\end{array}$ & $\begin{array}{c}\text { SL with } \\
\text { corr. Eq. } \\
10^{3} \text { tonnes }\end{array}$ & $\begin{array}{c}\text { Error } \\
\%\end{array}$ \\
\hline $\begin{array}{c}\text { Load from 97 days with } \\
\text { measurements, in } 10^{3} \text { tonnes }\end{array}$ & 140 & 140 & \\
\hline \hline One single daily rating & 103 & -26.43 & 136 & -2.86 \\
\hline
\end{tabular}

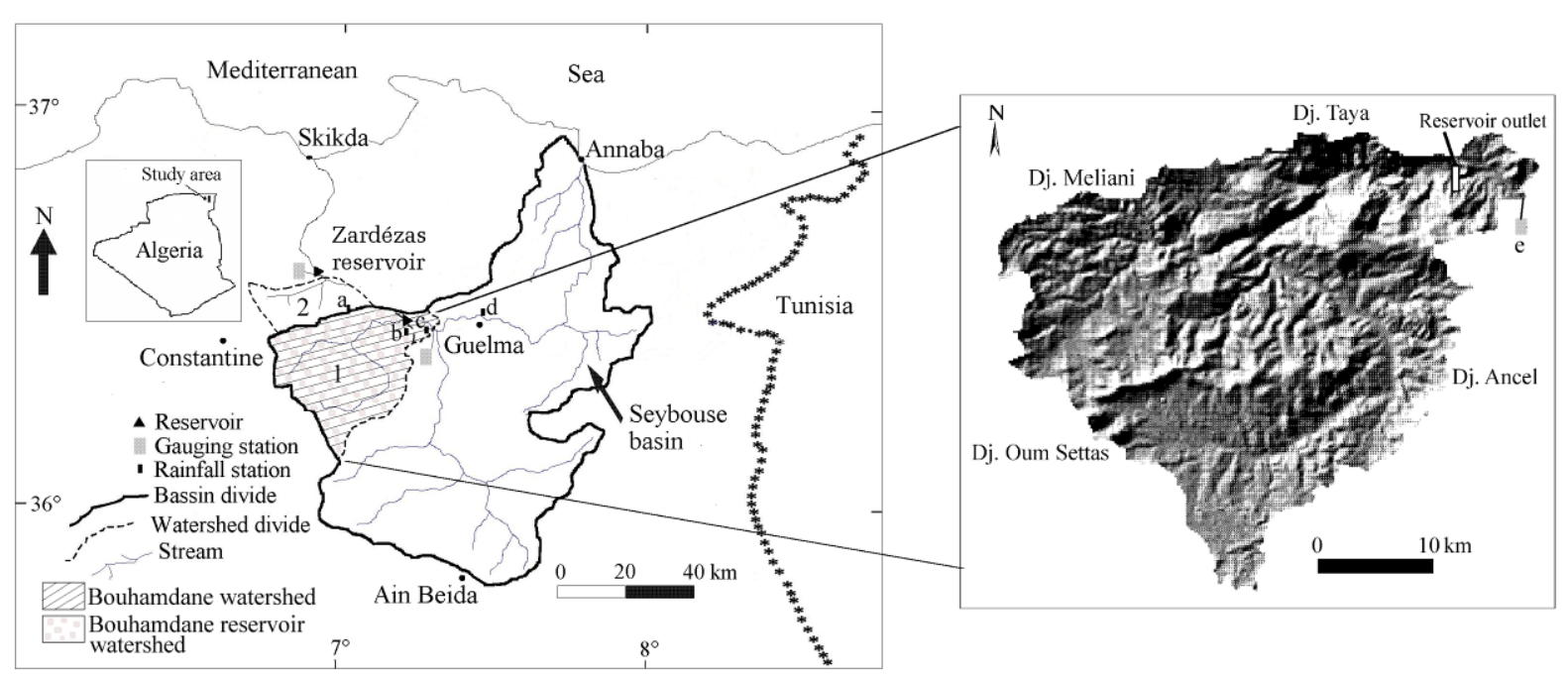

Figure 1. Location map of the : 1- Bouhamdane watershed; 2- Saf Saf watershed; a- Ouled Habeba rainfall station; b- Bouhamdane rainfall station; c- Medjez Amar rainfall station; d- Guelma rainfall station; e- Medjez Amar gauging station 

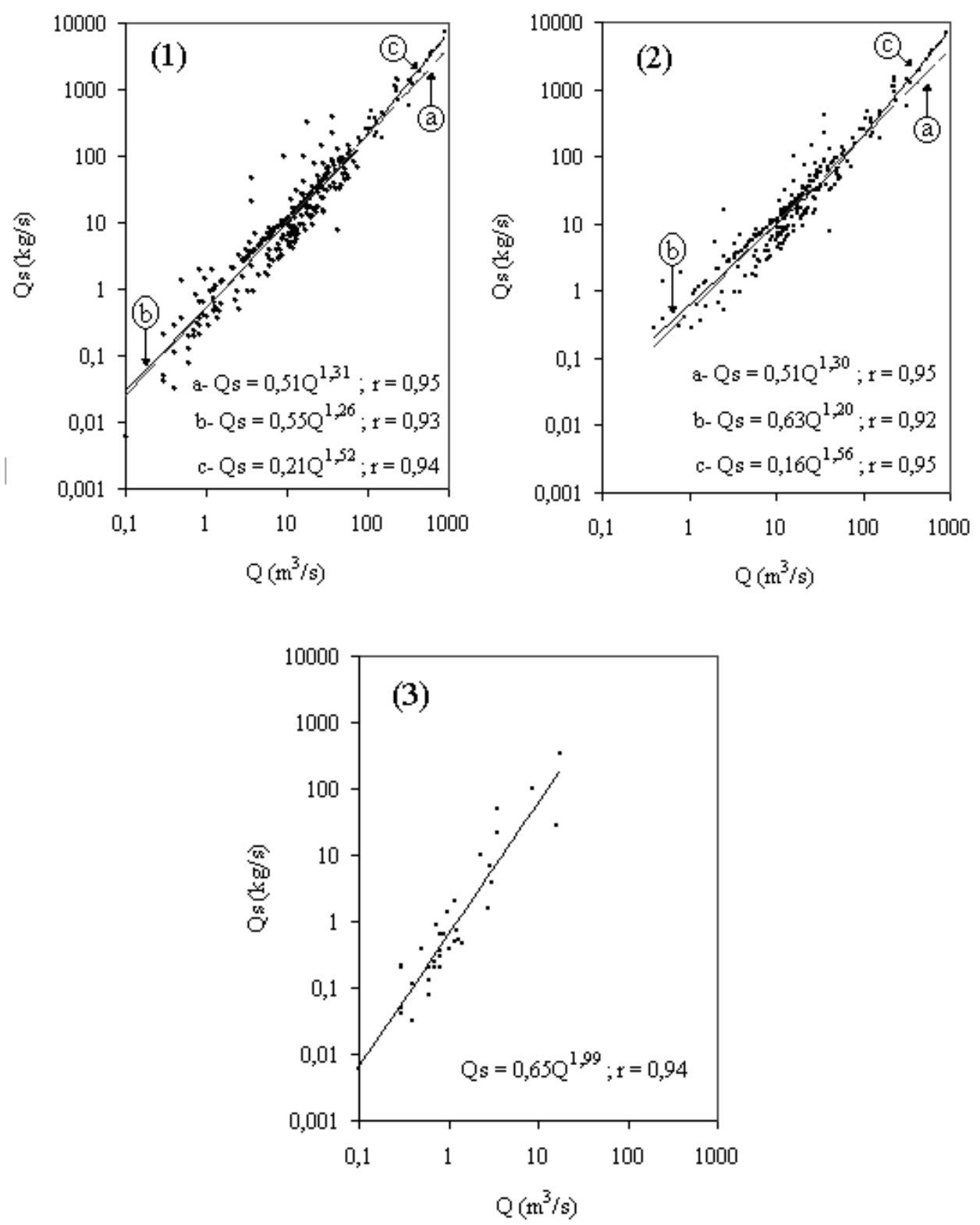

Figure 2. Relation of daily water discharge and daily sediment discharge according to : (1) single rating; (2) wet season; (3) dry season; a) rating from a single best-fit calculation; b) rating from low-medium flow; c) rating from high-flow. No high-flow and discharge-sediment threshold during dry season so just a single regression is represented 

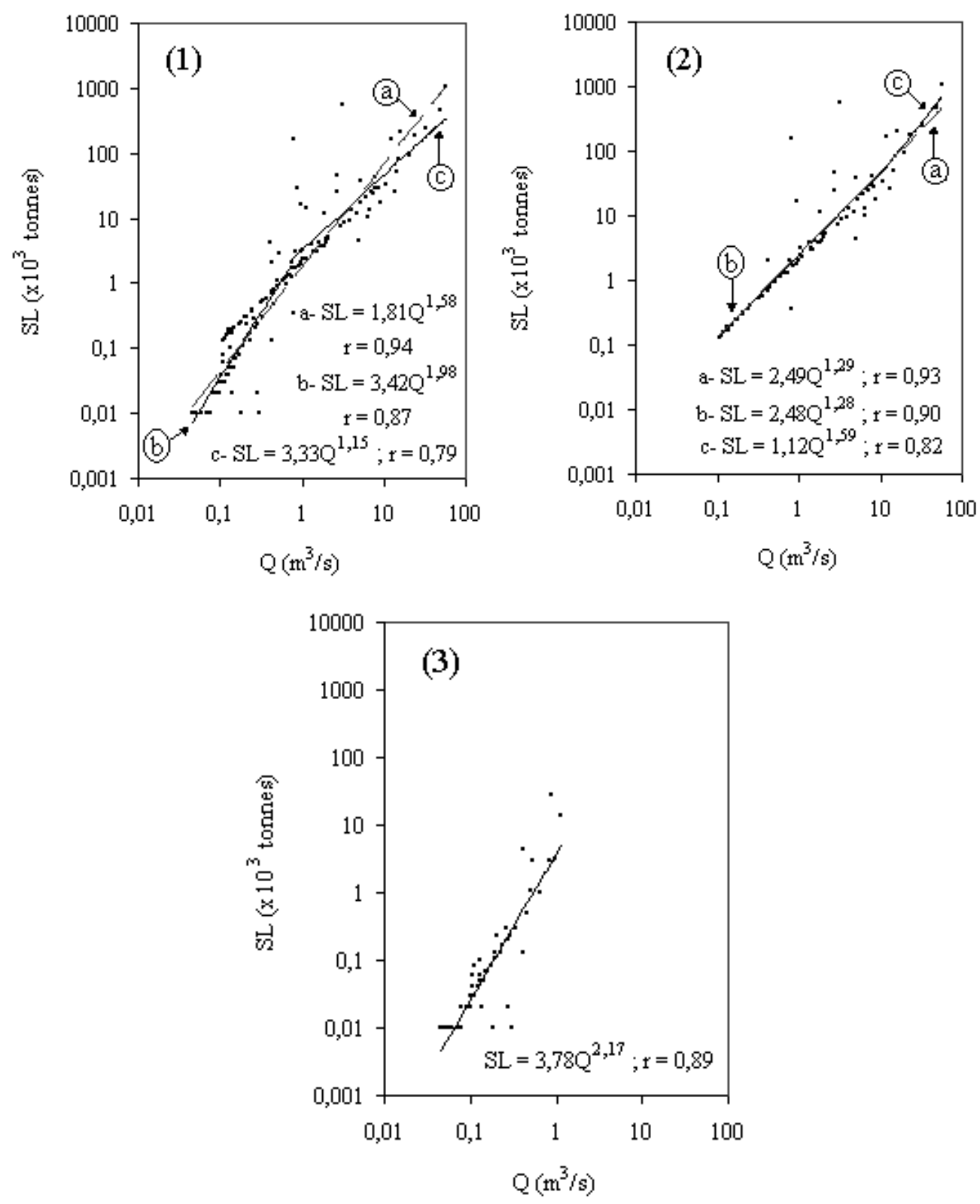

Figure 3. Relation of monthly discharge and monthly sediment load according to: (1) single rating; (2) wet season; (3) dry season; a) rating from a single best-fit calculation; b) rating from low-medium flow; c) rating from high-flow. No high-flow and discharge-sediment threshold during dry season so just a single regression is represented 


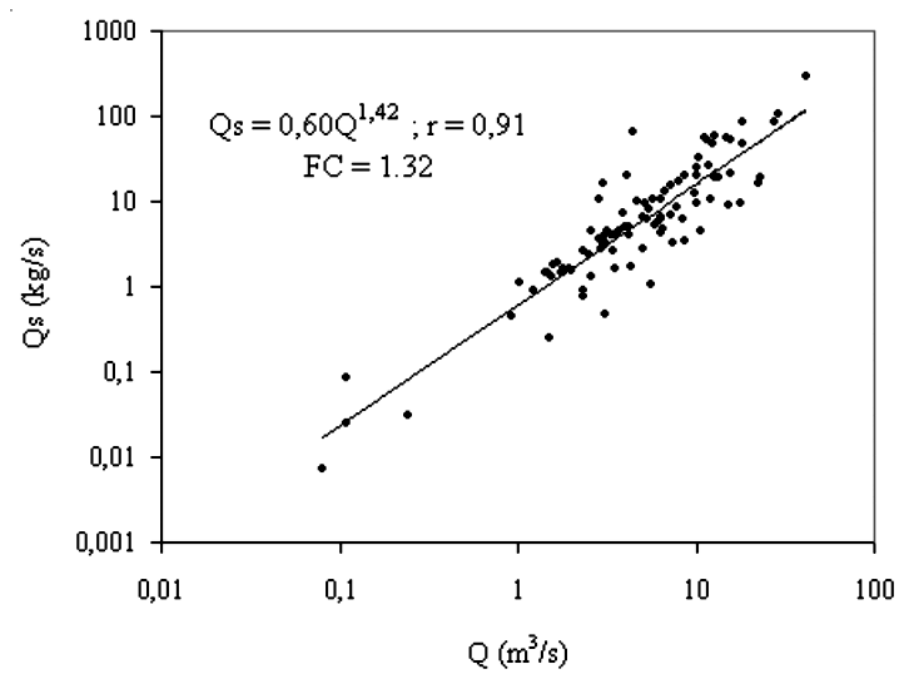

Figure 4. Relation of daily mean water discharge and daily sediment discharge for the Saf Saf watershed

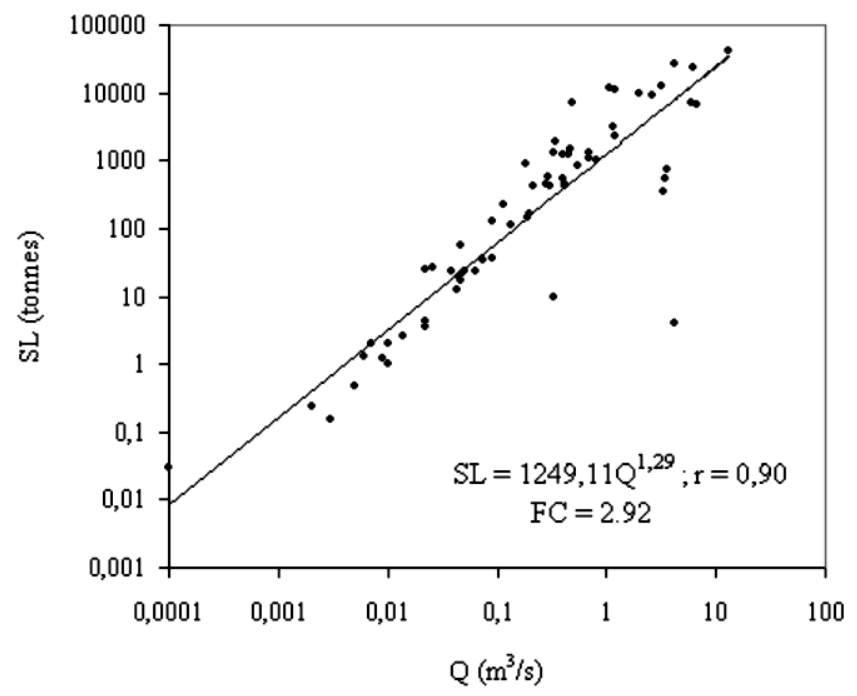

Figure 5. Relation of monthly mean discharge and monthly sediment load for the Saf Saf watershed 